\title{
STRATEGI REORIENTASI KURIKULUM PENDIDIKAN MATEMATIKA DI ERA REVOLUSI INDUSTRI 4.0
}

\author{
Dona Fitriawan ${ }^{1}$, Mohammad Rif'at $^{2}$, Agung Hartoyo ${ }^{3}$, Silvia Sayu $^{4}$, Hamdani $^{5}$, Yulis Jamiah $^{6}$ \\ ${ }^{122334) 556)}$ Pendidikan Matematika FKIP Universitas Tanjungpura, Pontianak, Indonesia
}

Corresponding Author: Dona Fitriawan, donafitriawan@ fkip.untan.ac.id

\begin{abstract}
Abstrak: Kegiatan PKM berasal dari kondisi dan potensi industri di Provinsi Kalimantan Barat (BPS, 2018). Industri tersebut antara lain adalah smelter, agrobisnis, pengolahan karet, pengolahan ikan dan tangkapan air lain, pengolahan kelapa sawit, pengolahan kayu, pariwisata, dan manufaktur. Dari segi fisik, penempatan industri-indistri tersebut telah sesuai dengan tata ruang dan wilayah, yakni pengelolaan kepada layak dan kelestarian lingkungan sosial dan alam. Dengan adanya industri sebagaimana dimaksud, rerata pertumbuhan ekonomi di Kalimantan Barat adalah 4,95\%. Angka pertumbuhan ekonomi tersebut adalah relevan dengan kebutuhan matematika industri, terutama matematika sekolah samapai tingkat SMA/sederajat. Relevansi PKM ini terhadap kondisi dan potensi pembanguanan industri di Kalimantan Barat adalah bahwa: (1) pertumbuhan industri meningkat rerata sebesar 0,5\% per tahun, dilihat dari pertumbuhan jenis dan skala industri dan (2) peningkatan jumlah tenaga kerja di bidang industri meningkat rerata $2 \%$ per tahun dari seluruh angkatan kerja dari lulusan satuan pendidikan SMP, SMA, dan sederajat serta lulusan perguruan tinggi. Terdapat tiga (3) prioritas utama yakni: (1) pertumbuhan berarti, dengan mengembangkan ekonomi berbasis pengetahuan dan inovasi; (2) pertumbuhan berkelanjutan, dengan mempromosikan sumber-sumber yang efisien, lebih hijau (ramah lingkungan), dan ekonomi kompetitif; dan (3) pertumbuhan inklusif, dengan membina kegiatan dan perkerjaan perekomian skala tinggi yang memberikan sumbangan besar pada pertumbuhan ekonomi, sosial dan keterpaduan wilayah.
\end{abstract}

Kata Kunci: Pendidikan Matematika, Era Revolusi Industri 4.0, Reorientasi Kurikulum.

Abstract: PKM activities are based on the conditions and potential of the industry in West Kalimantan Province. These include smelters, agribusiness, rubber processing, fish and other water cathment processing, palm oil processing, wood processing, teorism and manufacturing. From a physical perspective, the placement of these industries is in accordance with the spatial and regional layout, namely proper management and preservation of the social and natural environtment. With the existence of the industry as referred to, the average economic growth in West Kalimantan 4,95\%. This economic growth rate is relevant to the needs of industrial mathematics, espencially school mathematics up to SMA/ equivalent level. The relevance of this PKM to the conditions and potential for industrial development in West Kalimantan is that: 1) Industrial growth increases by an average of $0,5 \%$ per year, seen from the growth in the type and schale of industry and 2) the increase in the number of workers in the industrial sector increases on average $2 \%$ per year of the entire workforce from graduates of junior high school, high school and equivalent education units and university graduates. There are three (3) main priorities, namely: 1) meaningful growth, by developing an economy based on knowledge and innovation; 2) sustainable growth, by promoting efficient, greener (environmentally friendly) sources, and a competitive economy; and 3) inclusive growth, by fostering high-scale economic activities and work that make a major contribution to economic growth, social and regional integration.

Keywords: Mathematics Education, Industrial Revolution Era 4.0, Curriculum Reorientation

Submitted: 12-04-2021, Revised: 16-08-2021, Accepted: 28-09-2021 


\section{Pendahuluan}

Pendidikan di era revolusi industri 4.0 adalah kegiatan orang dewasa untuk membimbing dan mengarahkan orang lain agar bisa belajar untuk diri mereka sendiri”. Untuk itu, bidang pendidikan secara keseluruhan harus mampu menciptakan lingkungan dan situasi di mana seseorang dapat memunculkan berbagai potensi dan kemampuan mereka sendiri. Tidak cukup sampai di situ, pendidikan juga harus mampu mengasah kemampuan yang mereka miliki untuk menciptakan pengetahuan mereka sendiri, menafsirkan dunia dengan cara unik mereka sendiri, dan akhirnya menyadari potensi penuh atas diri mereka. Dengan demikian, setiap orang dituntut untuk dapat memahami potensi diri, mengembangkan potensi yang dimiliki melalui pengembangan pengetahuan dan keterampilan yang terkait dan selanjutnya menciptakan sesuatu yang baru untuk dirinya sendiri (Suwardana, 2018).

Untuk dapat menghasilkan karya-karya inovasi, seseorang memerlukan proses belajar yang dapat memaksimalkan potensi setiap individu, memberi fasilitas dan akses yang sesuai dengan minat dan bakatnya dalam belajar, termasuk dalam bidang keahlian pendidikan matematika. Skill bermatematika dari setiap individu dapat tersalurkan dengan baik secara terus menerus melalui berbagai jejaring sosial yang maksimal hidup dalam ruang online. Hal ini dapat berupa sekadar menyelesaikan soal aplikasi matematika yang ada di ruang kelas, atau dapat juga menciptakan perangkat lunak perihal aspek knowing mathematics atau mathematical knowledge dan aspek doing mathematics mathematization atau mathematical practice. Jika memang tantangan 'era industry 4.0' ditandai dengan sistem siber-fisik; kemajuan teknologi informasi dan komunikasi; jaringan komunikasi; big data dan cloud computing; peningkatan kemampuan peralatan untuk interaksi kooperasi manusia-komputer; serta ditandai dengan modeling, virtualization, dan simulation, maka tantangan itu dapat terjawab secara tunai dengan menjadi seorang wirausahawan yang memiliki visi misi komprehensif. (Hakim, 2019; Kemenristekdikti, 2018).

Kurikulum 2013 dimaksudkan untuk memenuhi tuntutan perwujudan konsepsi pendidikan yang bertumbu pada perkembangan peserta didik beserta konteks kehidupannya sebagaimana dimaknai dalam konsepsi pedagogik transformatif. Konsepsi ini menuntut bahwa kurikulum harus didudukkan sebagai wahana pendewasaan peserta didik sesuai dengan perkembangan psikologisnya dan mendapatkan perlakuan pedagogis sesuai dengan konteks lingkungan dan jamannya (Fernandes, 2019). Hadirnya Revolusi 4.0 pada abad 21 ini membawa arah baru pendidikan di Indonesia yaitu rumusan framework pembelajaran abad ke-21 yang disebut dengan Indonesian Partnership for 21 Century Skill Standard (IP-21CSS) (Safitri, 2019). Dalam framework tersebut dinyatakan bahwa penekanan pembelajaran harus pada pengembangan keterampilan 4C diantaranya critical-thinking and problem-solving skills, (communication and collaboration skills, (c) creativity and innovation skills). Selain itu pada kurikulum 2013 juga dikembangkan literasi teknologi informasi dan komunikasi, serta penguatan pendidikan karakter pada pengembangan karakter (character building) dan nilai spiritual (spiritual value).

Hasil kegiatan PKM dapat dimanfaatkan oleh pihak sekolah (secara khusus Guru Matematika), Program Studi Pendidikan Matematika jenjang sarjana, magister, dan doktor (secara umum adalah LPTK di bawah jurusan PMIPA), peneliti, dan pengambil kebijakan (WTEC, 2019). Pengambil kebijakan (termasuk organisasi yang dapat mendanai) memiliki gambaran yang jelas mengenai kegiatan matematika melalui institusi penyelenggara untuk inovasi melalui koordinasi dari infrastruktur penelitian virtual. Untuk mengatasi fragmentasi geografis dan ilmu pengetahuan, institusi akademik dan industri dapat berbagai dan mendiseminasikan praktik terbaik lintas provinsi Kalimantan Barat dan lintas disiplin melalui jaringan kerja dan sarana digital. Masyarakat matematika dan institusi akademik dapat 
membuat (atau menyusun) kurikulum secara umum dan program pendidikan dalam matematika pada level provinsi yang mempertimbangkan keahlian dan kekhususan wilayah (BPS, 2018).

Apa yang dibutuhkan prodi pendidikan matematika dalam Era Revolusi Industri 4.0 yaitu terdapat tiga prioritas utama (OECD, 2008), yakni: 1) Pertumbuhan, berarti dengan megembangkan ekonomi berbasis pengetahuan dan inovasi; 2) Pertumbuhan Berkelanjutan, dengan mempromosikan sumber-sumber yang efisien, lebih hijau (ramah lingkungan), dan ekonomi kompetitif; dan 3) Pertumbuhan Inklusif, dengan membina kegiatan dan pekerjaan perekonomian skala tinggi yang memberikan sumbangan besar pada pertumbuhan akonomi, social, dan keterpaduan wilayah.

\section{Metodologi}

Metode yang digunakan adalah dengan teknik observasi dan instrumen angket ke mahasiswa S1, S2, Dosen dan Guru matematika, serta dunia usaha yang terkait dengan bidang matematika. Khalayak sasarannya berupa mahasiswa S1, S2, Dosen dan Guru matematika, serta dunia usaha yang terkait dengan bidang matematika. Dana PNBP FKIP Untan Tahun 2020 untuk kegiatan PKM unit prodi dilaksanakan agar prodi mengoordinasikan kelompok unggulan dalam matematika industri dan menyusun perkuliahan matematika untuk inovasi, yang kemudian disampaikan kepada pengguna. Prodi mempersiapkan Tim Strategi untuk Inovasi dan Matematika (TSIM) agar mengembangkan strategi yang tepat (cocok) untuk matematika dalam industri.

Prodi mengidentifikasi matematika industri dan terapan sebagai prioritas penyilangan untuk kerangka kerja reorientasi kurikulum. Prodi (atau LPTK) dan industri memfasilitasi mobilitas pekerjaan antara akademisi dan perusahaan-perusahaan. Akademisi menyusun kurikulum untuk matematika industri dan mengatur pendapatan atau pemikiran dari pengguna matematika industri. Mereka mengembangkan kriteria baru untuk menilai dan mengenal karir dalam matematika industri.

Masyarakat matematika dalam kolaborasi dengan industri menyusun jurnal khusus untuk matematika industri dan dikontribusikan untuk perpustakaan matematika. Peneliti dalam dunia industri dan akademisi menyesuaikan pola pikir pengguna berkenaan dengan domain matematika berbeda dalam melakukan kegiatan (berinteraksi), dan mendiseminasikan praktik terbaik. Masyarakat matematika dan industri bekerja sama terkait peluang nyata dalam kompetisi tema matematika dan industri.

\section{Hasil dan Pembahasan}

Pelaksanaan penelitian ini dilakukan mulai bulan Mei sampai dengan November 2020. Dari Kegiatan PKM tersebut diperoleh hasil dan pembahasan sebagai berikut:

\section{A. Hasil}

Hasil yang diperoleh dari PKM ini adalah sebagai berikut:

Tabel 1. Pemeringkatan Reorientasi Kurikulum

\begin{tabular}{|c|l|c|c|c|c|c|}
\hline \multirow{2}{*}{ No } & \multirow{2}{*}{ Responden } & \multirow{2}{*}{$\begin{array}{c}\text { Jumlah } \\
\text { Responden }\end{array}$} & \multicolumn{3}{|c|}{$\begin{array}{c}\text { Nomor Butir pada } \\
\text { Skor }\end{array}$} & \multirow{2}{*}{$\begin{array}{c}\text { Jumlah } \\
\text { Skor }\end{array}$} \\
\cline { 4 - 7 } & & $\mathbf{1}$ & $\mathbf{2}$ & $\mathbf{3}$ & \\
\hline 2 & $\begin{array}{l}\text { Guru Matematika } \\
\text { Mahasiswa S2 Pendidikan } \\
\text { Matematika }\end{array}$ & 10 & 0 & 5 & 5 & 25 \\
\hline
\end{tabular}




\begin{tabular}{|l|l|c|c|c|c|c|}
\hline 3 & Dosen Jurusan Pendidikan MIPA & 5 & 0 & 2 & 3 & \multicolumn{1}{|c|}{13} \\
\hline 4 & Dosen Jurusan MIPA & 5 & 0 & 0 & 5 & 15 \\
\hline 5 & Pihak Industri & 5 & 0 & 0 & 5 & 15 \\
\hline 6 & Pemerintah & 2 & 0 & 0 & 2 & \multicolumn{2}{|c|}{} \\
\hline 7 & Dunia Usaha & 5 & 0 & 5 & 0 & \multicolumn{1}{|c}{} \\
\hline \multicolumn{2}{r|}{ TOTAL } & 52 & 0 & 27 & 25 & 129 \\
\hline
\end{tabular}

Melalui kolaborasi, semua kelompok responden tidak memberikan pertimbangan rendah, artinya semuanya memerlukan reorientasi kurikulum matematika dalam industri. Peringkat kedua dan ketiga relative berimbang, yang dapat dimaknai bahwa semua kelompok responden sangat mementingkan reorientasi kurikulum matematika, baik level sekolah menengah maupun perguruan tinggi.

Kecenderungan pilihan peringkat reorientasi kurikulum adalah yang tertinggi, atau dapat dipandang sebagai fungsi linear naik, dari dunia usaha kepada guru matematika. Akan tetapi, untuk dosen MIPA, pihak industry, dan pemerintah sangat menginginkan melakukan reorientasi kurikulum, terutama untuk kepentingan dunia industri.

Penyajian menggunakan diagram batang disajikan pada Gambar 1.

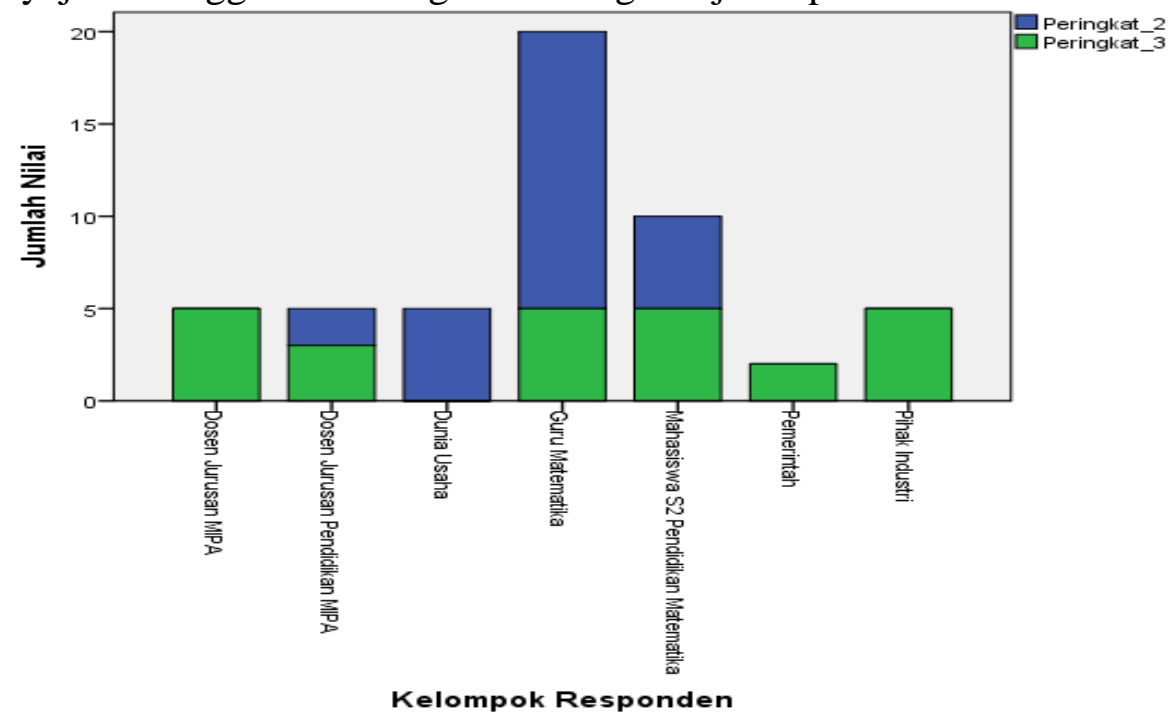

Gambar 1. Kelompok Responden

Dari diagram tersebut, dapat diamati bahwa dosen jurusan PMIPA, pemerintah, dan pihak industri sangat mementingkan reorientasi kurikulum matematika terutama untuk kepentingan dunia industri. Sementara dosen jurusan PMIPA mementingkan reorientasi pada pertimbangan sedang, yang berarti bahwa mereka masih memerlukan lebih banyak penyajian materi matematika untuk kepentingan matematika atau berpikir matematis.

Dunia usaha tampak belum begitu memerlukan pilihan paling penting. Hal ini dapat dipahami bahwa dunia usaha menggunakan teknologi siap pakai untuk menjalankan usahanya, serta relatif bahwa persoalan teknologi yang dihadapi tidak lebih cepat daripada dunia industry. Yang menarik adalah pertimbangan dari mahasiswa program magister pendidikan matematika. Mereka mengutamakan reorientasi kurikulum atau memberikan pertimbangan paling tinggi atau mendesak. 


\section{B. Pembahasan}

Pertimbangan mengenai pengetahuan isi adalah paling menarik. Semua kelompok responden memberikan pertimbangan penting untuk semua pengetahuan isi. Perbedaannya adalah pada peringkatnya. Sebagai contoh, tertinggi adalah bidang terapan kehutanan, kemudian kesehatan lingkungan, kemudian kesehatan dan keamanan pekerja, teknik sipil, dan elektronika. Pilihan untuk peringkat tertinggi tersebut diputuskan oleh sebanyak 40 responden dari semua kekompok.

Peringkat kedua adalah teknologi makanan, teknik penambangan, dan teknik mekanika. Peringkat kedua ini dipilih oleh sebanyak 34 responden dari semua kelompok. Hal ini dapat dimengerti karena jumlah industry tersebut lebih sedikit dibandingkan dengan pilihan peringkat pertama.

Begitu pula untuk bidang terapan lain, ditetapkan sebagai pilihan ketiga dan keempat. Peringkat ketiga adalah elektronika, sains kimia, grafik dan CAD, serta geomatika. Peringkat ketiga ini memang masih sesuai dengan ketinggian teknologi yang digunakan dalam industry. Akan tetapi, elektronika dapat dipandang anomaly karena hamper semua industry dan dunia usaha menggunakan atau ada urusan elektronika dan relative paling menonjol.

Sisa bidang terapan masih dipilih oleh responden. Yang menarik adalah teknik biomedis, dipahami sejalan dengan perkembangan industry layanan kesehatan di Kalimantan Barat. Prostetika dan robot memang relative belum digunakan pada industry di Kalimantan Barat, akan tetapi sebanyak 10 responden memilihnya.

Setelah dikolaborasikan, ternyata teknologi robot yang masih mengandalkan teknik mekanika memang ada dan diperlukan. Inilah sebabnya mengapa teknik mesin menjadi pilihan penting juga dalam reorientasi kurikulum.

Memang ternyata bidang akademis dan industri bergantung pada pengetahuan matematika untuk membuka berbagai temuan lanjut. Kolaborasi untuk reorientasi kurikulum ini memberikan sumbangan pada bidang kerja lebih luas seperti kesehatan. Tantangannya adalah bahwa aspek akademis dan industri memang sangat kompleks dimana masalah hanya dapat diselesaikan melalui bantuan dan keikutsertaan ilmuwan matematika.

Inisiatif memang sangat diperlukan untuk melibatkan berbagai kelompok ilmuwan. Tentu akan dapat dilakukan secara bersama-sama dengan masyarakat, yakni dunia usaha dan dunia industry dan secara khusus kelompok ilmwan terapan. Lebih jauh lagi, masyarakat matematika (guru dan dosen) bersama industry perlu terlibat dalam stase masing-masing yang berbeda-beda. Sebagai tambahan, kolaborasi yang dilakukan sudah melaunsing antara Ilmuwan dan praktisi serta pemerintah (pengambil kebijakan) dalam berbagai sector industri.

Hasil kolaborasi merupakan suatu bentuk kontribusi dari berbagai responden yang berkepentingan termasuk pengambil kebijakan yang terefleksi dalam laporan ini. Ke depan tentu berkontraksi dari kekuatan keyakinan responden yang potensial untuk memperoleh nilai tambah ekonomi, membantu melakukan inovasi, dan dengan demikian kapasitasnya adalah untuk pasar global.

Untuk memanfaatkan potensi industri, perhatian perlu diberikan pada pengurangan sekat-sekat geografis dan ilmiah (literasi sains). Untuk mengatasi sekatan tersebut diperlukan keterlibatan seluruh masyarakat dan dari pihak industri. Kita memerlukan penggabungan pengalaman dan sinergitas yang saling bertatapan antara matematika dan industri serta menciptakan wilayah interaksi untuk mengambil kembali peluanmg ke dalam kesempatankesempatan baru (Suwardana, 2018).

Kita perlu mempertimbangkan isu sinergitas yang merupakan mesin penggerak utama menuju kepada latihan-latihan terampil. Kita perlu mengenali kelompok yang melakukan kegiatan penting dalam bidang matematika industri dan mendatangkan ilmuwan matematika 
melalui perguruan tinggi untuk menampilkan pengetahuan, keterampilan serta sikap dari pengalaman-pengalaman bersama untuk mendapatkan keberhasilan dalam kerjasamanya dengan dunia industry.

\section{Simpulan}

Dari hasil pelaksanaan dan pembahasan, dapat disimpulkan bahwa: 1) Hasil kolaborasi merupakan suatu bentuk kontribusi dari berbagai responden yang berkepentingan termasuk pengambil kebijakan yang terefleksi dalam laporan ini. Ke depan tentu berkontraksi dari kekuatan keyakinan responden yang potensial untuk memperoleh nilai tambah ekonomi, membantu melakukan inovasi, dan dengan demikian kapasitasnya adalah untuk pasar global. 2) Inisiatif memang sangat diperlukan untuk melibatkan berbagai kelompok ilmuwan. Tentu akan dapat dilakukan secara bersama-sama dengan masyarakat, yakni dunia usaha dan dunia industry dan secara khusus kelompok ilmwan terapan. Lebih jauh lagi, masyarakat matematika (guru dan dosen) bersama industry perlu terlibat dalam stase masing-masing yang berbeda-beda. Sebagai tambahan, kolaborasi yang dilakukan sudah melaunsing antara Ilmuwan dan praktisi serta pemerintah (pengambil kebijakan) dalam berbagai sector industri.

\section{Ucapan Terima Kasih}

Ucapan terimakasih kami sampaikan kepada: 1) Pihak Fakultas yang telah membiayai pkm ini dengan dana DIPA PNBN FKIP Untan, 2) Mahasiswa berjumlah 8 orang yang membantu kegiatan PKM ini, 3) Semua pihak yang terkait sehingga PKM ini dapat terselesaikan dengan baik.

\section{Daftar Pustaka}

Bps. (2018). Keadaan angkatan kerja di provinsi kalimantan barat. In badan pusat statistik kalimantan barat.

Fernandes, r. (2019). Relevansi kurikulum 2013 dengan kebutuhan peserta didik di era revolusi industri 4.0. Jurnal socius (jurnal of sosiology research dan education, 6(2), 31.

Hakim, a. . (2019). Menjawab tantangan era revolusi industri 4.0 dengan menjadi wirausahawan di bidang pendidikan matematika. Prosiding seminar nasional pendidikan kaluni januari 2019., 2(2), 121.

Kemeristekdikti. (2018). Pengembangan iptek dan pendidikan tinggi di era revolusi industri 4.0. Ristekdikti.

Oecd. (2008). Global science forum: report on "mathematics in industry". July 2008. In www.math.cmu.edu/cna/publications/publiscations2000/027abs/00-cna-027.ps.

Safitri, n. (2019). Pendidikan indonesia menyongsong era revolusi industri 4.0. Jurnal tadris matematika iain tulungagung, 8(2), 54.

Suwardana, h. (2018). Revolusi industri 4.0 berbasis revolusi mental. Jati unik: jurnal ilmiah teknik dan manajemen industri. Https://doi.org/10.30737/jatiunik.v1i2.117

Wtec. (2009). International assessment of research and development in simulation based engineering and science. In panel report. 